\title{
DESENVOLVIMENTO TERRITORIAL RURAL: UMA ANÁLISE DA EQUIDADE DE GÊNERO NO MUNICÍPIO DE CONCEIÇÃO DO COITÉ
}

\author{
$\underline{\text { Maria Carolina de Oliveira Silva }}{ }^{1}$; Acácia Batista Dias², Ildes Ferreira de Oliveira ${ }^{3}$ \\ 1.Bolsista PIBIC/CNPQ, Graduanda em Psicologia, Universidade Estadual de Feira de Santana, e-mail: \\ caroliina002@hotmail.coom \\ 2.Orientadora. Departamento de Ciências Humanas e Filosofia, Universidade Estadual de Feira de Santana, \\ e-mail: acaciabatista02@gmail.com \\ 3.Coordenador do Projeto Ser Tão Forte: Desenvolvimento Territorial Sustentável, Departamento de Ciências \\ Humanas e Filosofia, Universidade Estadual de Feira de Santana, e-mail:ildesferreira@gmail.com
}

PALAVRAS-CHAVE: mulheres, território do sisal, políticas públicas.

\section{INTRODUÇÃO}

Este estudo está vinculado ao projeto "SER TÃO FORTE: Desenvolvimento Territorial Sustentável", apoiado pela Chamada Pública CNPq/MDA/SPM-PR No 11/2014 - Núcleos de Extensão em Desenvolvimento Territorial (NEDET).

Atualmente na Bahia existem 27 Territórios de Identidade, que em sua maioria abrange municípios que possuem características físicas, sociais, econômicas e históricas semelhantes, trata-se de uma divisão geopolítica. (BLATT; GONDIM, 2013). No entanto, esta pesquisa se direcionou ao Território de Identidade do Sisal, particularmente ao município de Conceição do Coité. Este território localiza-se no semiárido baiano, é constituído por 20 municípios e caracterizado pela predominância de uma economia agrícola de base familiar (IBGE,2011), na qual se inclui a cultura do sisal. Segundo Oliveira e Dias (2015), a população deste território vivencia ainda condições sociais adversas, já que atualmente os capitais públicos e privados são voltados para as áreas de maior poder econômico, sustentando e intensificando as desigualdades regionais e sub-regionais. O município de Conceição de Coité possui uma área de $1.086,22$ km², uma população de 62.040 hab., segundo o último censo demográfico (2010), sendo que as mulheres correspondem a 50,5\% desse total. (SEI, 2016)

Nesse município, as mulheres das áreas rurais apresentam uma significativa representatividade em associação e/ou grupos produtivos formados exclusivamente ou na sua maioria por mulheres. Estes grupos tem como propósito alcançar o reconhecimento, e visibilidade, ampliar a participação feminina na economia e combater as desigualdades de gênero. Essa expressividade das organizações coletivas deve-se ao fortalecimento dos movimentos sociais na Bahia, que por sua vez teve como principal influência o movimento de mulheres, cuja pauta de reinvindicação opõe-se a desigualdade de gênero, aos papéis estabelecidos pela sociedade patriarcal, e estimula a busca feminina por uma maior autonomia.

No meio rural, o homem costuma ser o responsável pelo controle da unidade produtiva e pela tomada da maioria das decisões, já as mulheres, mesmo participando da produção, não possuem o reconhecimento de suas atividades, que são consideradas como uma "ajuda" às atividades masculinas. A invisibilidade do trabalho feminino, especialmente no âmbito da casa e da roça, está associada à perspectiva de ausência de valor econômico e social, e quando estas proporcionam alguma rentabilidade tendem a ter um valor menor ao do homem. (MELO, 2002)

A pesquisa aqui desenvolvida teve como objetivo principal analisar os grupos de mulheres existentes no município de Conceição do Coité a partir do ramo de atividade e/ou 
produção, observando a forma de organização e pauta de reivindicação em prol da equidade de gênero.

\section{MATERIAL E MÉTODOS}

A pesquisa foi desenvolvida por meio de uma abordagem qualitativa, a qual buscou mapear os grupos produtivos e os principais motivos de adesão das mulheres na construção de um trabalho coletivo. Buscou-se também identificar a participação dessas mulheres nos Programas Sociais e nas Políticas Públicas específicas para as mulheres rurais.

Iniciou-se o percurso metodológico com leituras direcionadas, o que tornou possível uma maior proximidade com o tema e criticidade do mesmo, principalmente no que se refere à condição de invisibilidade e opressão vivenciada pelas mulheres rurais. Em seguida realizouse um mapeamento das políticas públicas elaboradas antes e depois da criação da Secretaria de Políticas para as Mulheres no Brasil, em 2003. Dentre estas, encontra-se programas como: Programa Nacional de Fortalecimento da agricultura Familiar (PRONAF MULHER), o PAA (Programa de Aquisição de Alimentos), dentre outros.

Além disso, utilizou-se o mapeamento dos grupos produtivos de mulheres, realizado pela equipe NEDET (14 grupos no total) para definir critérios de seleção de visitas e realização de entrevistas semiestruturadas com representantes de cada grupo. Antes de iniciar o contato com os grupos realizou-se uma entrevista com uma representante da Cooperativa dos Agricultores Familiares e do Empreendimento Solidário (COOAFES), que por sua vez é a instituição responsável pela comercialização dos produtos gerados pela maioria dos grupos de produção associados a ela. Durante a entrevista teve-se informação sobre grupos desfeitos.

As demais entrevistas ocorreram com integrantes dos grupos de produção e/ ou associação: Mãos de Fada, Mãos que Trabalham, Mulheres Guerreiras, Delícias da Terra, e Associação Comunitária da Região da Onça. Através dessas entrevistas, obteve-se informações sobre o histórico do grupo, números de componentes, programas sociais destinados à população rural e políticas específicas acessadas pelas mulheres. Além disso, foi possível conhecer as razões que mobilizaram a criação do grupo, o engajamento das mulheres e os benefícios proporcionados por essa inserção. Após a realização de cada entrevista, as mesmas foram transcritas, sistematizadas e analisadas.

\section{RESULTADOS E/OU DISCUSSÃO}

Através da pesquisa desenvolvida foi possível observar as desigualdades de gênero existentes nas áreas rurais do município de Conceição do Coité. Além disso, a pesquisa propiciou uma maior compreensão dos benefícios da participação das mulheres rurais no processo de produção coletiva. Percebeu-se que o engajamento das participantes nos grupos de produção do município, em geral, tem como principal objetivo a obtenção de renda, por meio da produção e comércio de produtos. Conforme foi demonstrado por uma participante da pesquisa: Porque assim, eu não trabalhava em nada, falei assim: vou tentar até quando der certo, não faço outra coisa mesmo. Aí comecei, até porque é uma renda familiar pra gente, é bom pra ajudar a família. Esse dinheirinho não é pouco? Mas sempre a gente faz alguma coisa. (A.F, 25 anos, integrante do Grupo Mãos que Trabalham). Além do aspecto mercantil, os grupos produtivos proporcionavam benefícios como: a ampliação do conhecimento, um reconhecimento pessoal e público, incentivo para determinada autonomia e liberdade, já que muitas estavam aprisionadas ao seu universo privado, ao mesmo tempo funcionavam como um espaço de solidariedade, amparo e companheirismo como nos relata M.G (32 anos, ensino médio completo, integrante do Grupo Mulheres Guerreiras). 
O dia que a gente passa separado, a gente sente até falta. A gente se diverte muito lá dentro, conta muita fofoca, piada, ri muito. Teve um caso de uma participante, que já teve até depressão, e lá não, ela disse que quando vai pra lá, parece que está em outro mundo, ela nem lembra que já teve, então até a autoestima da gente fica mais elevada. E mais, tem aquela questão de mulheres que diziam assim: Ah, eu nunca tinha saído, e com o grupo eu conheci mais pessoas, mais lugares, estou aprendendo coisas novas, coisas que a gente não via. Porque a gente sabe que só ficando aqui no Serrote, a gente não ver nada. Então é mais questão de conhecimento e de fazer amizades.

A inserção nesses grupos de produção propiciou um pequeno avanço na conscientização das integrantes, contribuindo para possíveis questionamentos da invisibilidade política, econômica e social nas quais estão historicamente submetidas.

Quanto às políticas públicas que as mulheres rurais tem acesso, as mencionadas foram: o Programa de Aquisição Alimentar (PAA), o Programa Nacional de Alimentação Escolar (PNAE), e o PRONAF MULHER, sendo esta última a única política específica que esta categoria acessava.

De acordo com Lima et al. (2003), o aumento dos números de acessos do Pronaf Mulher em todas as regiões revela um maior grau de informação, de preparo e de mobilização das mulheres, repercutindo no reforço das atividades produtivas das mulheres. Contudo, a pesquisa evidenciou a incipiência de acesso a muitas políticas, principalmente no que se refere àquelas específicas paras as mulheres rurais, como nos conta A.F (25 anos, grupo Mãos que Trabalham, ensino médio completo) ao relatar sobre o acesso ao PRONAF MULHER: Na verdade, aqui na região de Coité, ele é até um pouco desconhecido viu? É até pouco falado. Ninguém fala assim do PRONAF Mulher. A gente nem ver, ouve falar dificilmente.

Deste modo, segundo Heredia e Cintrão (2006), a análise das desigualdades e das condições de vida das mulheres rurais deve considerar as precárias condições de vida e de acesso às políticas públicas nas zonas rurais, principalmente nas regiões mais pobres do país, que atinge as mulheres rurais, intensificando ainda mais as assimetrias de gênero. Neste intuito, quando questionadas a respeito das políticas específicas direcionadas as mulheres, muitas relataram descontentamentos em relação a estas, denunciavam a falta de apoio e a existência de medidas necessárias para reduzir esse quadro de opressão, a criação de mais políticas públicas, a ampliação do conhecimento e de debates que visem tornar público as desigualdades de gênero, conforme demonstram os discursos a seguir:

[...] Políticas públicas. Isso aí, a gente sabe que é impossível não se buscar e brigar por isso. Cada dia que a gente acorda, é um processo diferente que a gente tem que dominar, reunir, trabalhar pra que eles cheguem até os menos favorecidos, principalmente aqueles que se acomodam de fato. E a gente tá aí constantemente, buscando melhor desenvolvimento. (J.S, 48 anos, integrante do Grupo Mãos de Fadas).

[...] Eu acho que primeiro é a questão do debate, tem que mostrar pra poder combater o preconceito mesmo. Esse grupo mesmo, a produção que elas fazem é basicamente o que dizem que mulher faz mesmo, o papel da mulher é esse, o de ser dona de casa, de cozinhar, entre outros. Até nisso existem o preconceito, acham que as mulheres têm que está em casa. Mesmo assim ainda é pouco a autonomia porque é um lugar que ainda se produz comida. Então esses debates ajudariam nesse sentido da independência. Acho que 
primeiro é a questão do debate mesmo, de mostrar esses direitos iguais que a gente luta tanto. (A. F., 25 anos, integrante do grupo de Goiabeira).

\section{CONSIDERAÇÕES FINAIS}

Com essa pesquisa, ficou ainda mais evidente a expressividade das organizações produtivas de mulheres, no município de Conceição do Coité, as quais ainda de forma incipiente caminham na busca da autonomia pessoal e financeira.

Além disso, foi perceptível a pequena quantidade de acesso às políticas públicas por essas mulheres, principalmente no que se refere àquelas específicas para as mulheres rurais, cuja razão registrada foi a falta de informações sobre seus direitos, e os critérios de acesso a essas políticas, o que se torna uma barreira na mudança da lógica hegemônica de poder e de hierarquia que nutre as desigualdades e, como resultado mantém a maioria das mulheres em condição de desigualdades e/ou dependência. Assim, durante a entrevista com as mulheres rurais o processo de conscientização coletiva, e debates a respeito das desigualdades de gênero, foi considerado pelas mulheres, a principal medida capaz de contribuir na minimização dessas desigualdades do município.

Acredita-se que a pesquisa contribuiu para atingir a proposta do projeto matriz que objetiva também o fortalecimento das organizações produtivas das mulheres rurais, através da mobilização e conscientização.

\section{REFERÊNCIAS}

BLATT, Nadir; GONDIM, Patrícia S. C. Territórios de Identidade no Estado da Bahia: uma análise da regionalização implantada pela estrutura governamental na perspectiva do desenvolvimento local e regional IN: Anais do I Colóquio Baiano Tempos, Espaços e Representações: abordagens geográficas e históricas. UESB, Vitória da Conquista, 14 a 16 de

out. 2013.

Disponível

em http://periodicos.uesb.br/index.php/coloquiobaiano/article/viewFile/2860/pdf_89,livro.

Acesso em 13 de setembro de 2016.

HEREDIA, Beatriz M. Alásia de; CINTRÃO, Rosângela P. Gênero e acesso a políticas públicas no meio rural brasileiro. Revista Nera, Presidente Prudente, v. 9, n. 8, p.1-28, jun. 2006.

INSTITUTO BRASILEIRO DE GEOGRAFIA E ESTATÍSTICA. Censo Demográfico 2010.Rio de Janiero:IBGE,2011.

LIMA; Elida et.all. Crédito Rural: uma análise da atuação e características do PRONAF MULHER. IN: Anais do VIII SOBER Nordeste. Pluralidades Econômicas Sociais e Ambientais: interações para reinventar o Nordeste rural. Parnaíba, 06 a 08 de nov. 2013. Disponível em: http://www.viiisoberne.com.br/anais/ARQUIVOS/GT5-134-7620131001234005.pdf. Acesso em 13 de setembro de 2016.

MELO; L. A. Injustiças de Gênero: o trabalho da mulher na agricultura familiar. Ouro Preto, Minas Gerais, 2002.

OLIVEIRA, Ildes F.; DIAS, Acácia B. Territórios de Identidade: Principais Dilemas do Processo de Gestão- O caso do Território do Sisal. Revista Eletrônica do Programa de Mestrado em Desenvolvimento Regional da Universidade do Contestado. SC, v. 5, n. 2, 2015, p.127-147

SUPERINTENDÊNCIA DE ESTUDOS ECONÔMICAS E SOCIAIS DA BAHIA. Indicadores. $\quad$ Salvador: $\quad$ SEI $2016 . \quad$ Disponível 
http://www.sei.ba.gov.br/site/resumos/indicadores/indicadores_2908408.pdf. Acessado em $16 / 10 / 2016$ 